\title{
The Interaction Between an Imposed Current and the Creep of Idealized Sn-Ag-Cu Solder Interconnects
}

\author{
CHRISTOPHER KINNEY, ${ }^{1,3}$ TAE-KYU LEE, ${ }^{2}$ KUO-CHUAN LIU, ${ }^{2}$ \\ and J.W. MORRIS ${ }^{1}$ \\ 1.-Department of Materials Science and Engineering, University of California, Berkeley, CA, \\ USA. 2.-Component Quality and Technology Group, Cisco Systems, San Jose, CA 95134, USA. \\ 3.-e-mail: kinney@berkeley.edu
}

\begin{abstract}
The work reported here concerns the effect of an imposed current on the creep of simple $\mathrm{Sn}-\mathrm{Ag}-\mathrm{Cu}$ interconnects. The samples employed were double-shear specimens that contained paired solder joints, $400 \mu \mathrm{m} \times 400 \mu \mathrm{m}$ in crosssection, $200 \mu \mathrm{m}$ in thickness, on $\mathrm{Cu}$. Different representative microstructures were prepared by electromigration and isothermal aging. Samples were tested with and without an imposed current, and at a variety of temperatures. These tests consistently yield two unexpected results. First, the relative increase in creep rate with current was nearly the same over a range of temperatures and variety of starting microstructures. Second, when tests were done at the same temperature (including the effect of Joule heating), the rate of creep was lower under imposed current than under isothermal conditions. These results are explained in the light of new data that show that the temperature within the joint is almost constant, even under a relatively high current density of $5500 \mathrm{~A} / \mathrm{cm}^{2}$. Given constant temperature and a microstructure that includes interfacial voids, the current depletes the joint of vacancies, lowering the average creep rate, and introducing observable heterogeneities in the creep pattern. The usual Dorn equation then provides a very useful basis for evaluating the change of creep rate with current.
\end{abstract}

Key words: $\mathrm{Sn}-\mathrm{Ag}-\mathrm{Cu}$, current, creep, electromigration, interconnects, vacancy gradients

\section{INTRODUCTION}

The emergence of Sn-rich $\mathrm{Sn}-\mathrm{Ag}-\mathrm{Cu}$ solders as leading candidates to replace leaded solders has led to a considerable body of work on their microstructure and properties. This work has included research on the generation of microstructural damage by the action of high current densities, ${ }^{1-3}$ the rate of creep deformation as a function of temperature and load, ,2,4-8 and development of interfacial intermetallics during solidification and aging. ${ }^{2,7-9}$ Since solder joints in service carry current while under load at moderate temperature, the coupling between these factors is important to joint reliability, and is the subject of the present investigation.

(Received March 12, 2009; accepted May 26, 2009;

published online June 16, 2009)
It is inevitable that temperature, load, and current will be coupled. Current raises temperature via Joule heating; both temperature and current induce microstructural changes, particularly in the nature and distribution of precipitates and interfacial intermetallics, which influence the electrical resistivity and the creep rate under load; and current induces the electromigration of vacancies that may significantly affect the diffusional processes that govern creep. None of these coupling terms is well understood.

In a recent paper ${ }^{1}$ we reported results on the influence of imposed current on the shear creep rates of geometrically simple $\mathrm{Sn}-\mathrm{Ag}-\mathrm{Cu}$ interconnects. Those tests produced two interesting results. The first was that the relative increase in creep rate due to a given current density was approximately the same for a variety of sample pretreatments and test conditions. This result suggests that the 
primary effect of current is independent of the interconnect microstructure.

Since Joule heating is an obvious source of enhanced creep rates under current, a second set of tests was done to compensate for Joule heating. The temperature increase in the samples due to Joule heating was measured at different current densities. Samples were then tested without current, but at the temperature reached by Joule heating. The samples tested under current crept more slowly than their isothermal counterparts, suggesting that electromigration actually lowered the creep rate at a given temperature.

While we were not able to provide a theoretical explanation for these phenomena in Ref. 1, we advanced two possible causes. First, we suggested that the current imposed across a heterogeneous microstructure might result in nonuniform heating, causing thermal gradients. Since thermal gradients will ordinarily affect creep, an inhomogeneous temperature profile might cause changes in the creep behavior like those observed. Second, we noted that electromigration might affect creep by changing the vacancy concentration. It is well known that, during electromigration, ions diffuse in the direction of electron flow, and there is a counterdiffusion of vacancies. ${ }^{2,3,10-12}$ The result can be a significant change in the vacancy concentration which, given the importance of vacancies to climbdominated creep, affects the creep rate.

The work reported here was done to investigate these possible factors and identify the primary causes of the anomalous creep behavior under current.

\section{EXPERIMENTAL PROCEDURES}

The solder joints tested in this work used a $\mathrm{Sn}-\mathrm{Ag}-\mathrm{Cu}$ alloy, SAC 305 (Sn-3.0Ag-0.5Cu in wt.\%). The specimens were double-shear creep specimens like that shown in Fig. 1. The specimens were made in the following way. Copper blocks were cut to $11 \mathrm{~mm} \times 13 \mathrm{~mm} \times 6 \mathrm{~mm}$ size, and their broad faces were polished to 4000-grit polishing cloth. The polished faces of the blocks were coated with flux, then matched together while separated by $200-\mu \mathrm{m}$ spacers. The composite block was placed in molten $\mathrm{Sn}-\mathrm{Ag}-\mathrm{Cu}$ at $360^{\circ} \mathrm{C}$ for $45 \mathrm{~s}$, then removed and cooled in air. Once cool, the block was polished to examine the quality of the solder joints. The block was placed in a precision cutter and cut into sheets roughly $500 \mu \mathrm{m}$ thick. The sheets were polished, then cut into rods. These rods were then polished to create double-shear samples with square

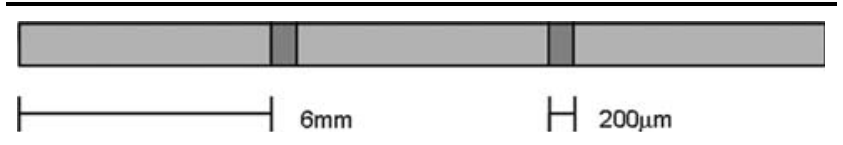

Fig. 1. Sample configuration. The cross-section is a square, approximately $400 \mu \mathrm{m} \times 400 \mu \mathrm{m}$.

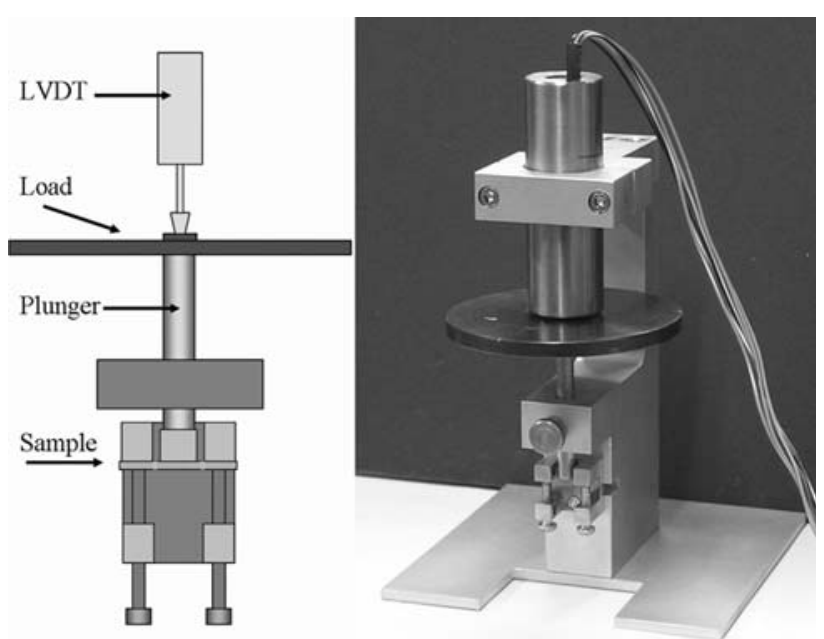

Fig. 2. The creep testing apparatus. The sample is loaded in shear as shown in the drawing on the left. The displacement is measured by the LVDT.

cross-sections, approximately $400 \mu \mathrm{m} \times 400 \mu \mathrm{m}$, and lengths of roughly $18.4 \mathrm{~mm}$. The lengths contained three $\mathrm{Cu}$ segments $6 \mathrm{~mm}$ in length connected by two solder joints of $200 \mu \mathrm{m}$ length, as illustrated in Fig. 1.

The samples were tested in the creep apparatus shown in Fig. 2. A constant load was placed on the sample, and the displacement was measured using an Omega linear variable displacement transducer (LVDT), with sub-10- $\mu \mathrm{m}$ resolution. The displacement measures the overall shear strain across the joint. Plotting the strain as a function of time reveals the creep rate, whose minimum value is the "steady-state" creep rate. In our tests a well-defined steady-state creep is ordinarily maintained for some time during the test.

The steady-state temperature of solder joints under current was measured experimentally and computed numerically. The measurements were done in two ways: by attaching thermocouples to the specimen, which give an average temperature, and by infrared (IR) imaging, which yields both a temperature and a thermal pattern. The expected temperature and thermal pattern were also computed numerically. For this purpose two- and threedimensional finite-element models of the samples were made. In addition to the sample's geometry, values were input for the thermal and electrical conductivities, the density, and the heat capacity for each phase. Heat transfer coefficients, the environmental temperature, and initial temperature were set as boundary conditions. Using finite-element analysis software, the temperature profiles of the system were calculated for various current densities.

To study the influence of microstructural evolution on the creep behavior, samples were aged in two ways. First, samples were thermally aged in an oven at $180^{\circ} \mathrm{C}$ for $200 \mathrm{~h}$. As will be described below, this treatment produced samples with coarsened 
intermetallic layers at the interfaces and coarse precipitates through the bulk. Second, samples were aged under current by applying a current density of $4 \times 10^{3} \mathrm{~A} / \mathrm{cm}^{2}$ at room temperature for $200 \mathrm{~h}$.

To study the deformation pattern during creep, samples were tested at constant load to various values of the total creep, then examined by scanning electron microscopy (SEM). The polished surfaces of the solder joints contained residual scribe marks that provided good fiducial marks to follow the creep pattern.

\section{RESULTS}

\section{The Influence of Current on Creep Rate}

The creep results from the original tests ${ }^{1}$ are reproduced in Fig. 3. When samples were tested under current, despite their different microstructures, the relative increase due to an imposed current of $5500 \mathrm{~A} / \mathrm{cm}^{2}$ is almost the same across all the samples (approximately $7 \times$ ). At a different temperature and load, the relative increase in the creep rate due to $5500 \mathrm{~A} / \mathrm{cm}^{2}$ is again $7 \times$.

To correct for the overall temperature increase due to Joule heating, the temperature of the solder joint was measured by attaching a thermocouple, and confirmed by infrared measurement with an IR camera as well as a finite-element computer model. For a sample in the as-cast condition, the temperature increased from $20^{\circ} \mathrm{C}$ (room temperature) to approximately $40^{\circ} \mathrm{C}$ at a current density of 4000 $\mathrm{A} / \mathrm{cm}^{2}$, and $50^{\circ} \mathrm{C}$ at a current density of $5500 \mathrm{~A} / \mathrm{cm}^{2}$. Samples were then tested without current in an oven at controlled isothermal temperatures of $40^{\circ} \mathrm{C}$ and $50^{\circ} \mathrm{C}$. Figure 4 compares the creep rates at these temperatures with the rates measured at the same load on samples at room temperature with $4000 \mathrm{~A} / \mathrm{cm}^{2}$ and $5500 \mathrm{~A} / \mathrm{cm}^{2}$ imposed current density.

Figure 4 shows that the steady-state creep rates under current are significantly below the isothermal creep rates at the same temperature, which suggests that the effect of current-induced electromigration is to reduce the rate of creep.

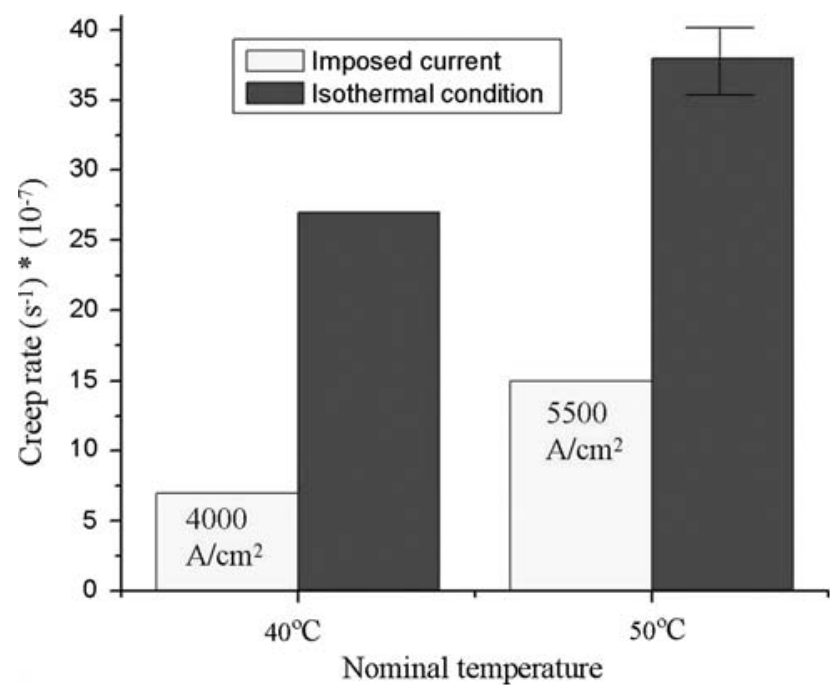

Fig. 4. Comparative rates of creep with an imposed current density, and during isothermal testing held at the temperature imposed by the current.

\section{Joint Thermal Profile}

To interpret these results we first considered the possibility that inhomogeneous Joule heating produced significant thermal gradients in the specimen that affected the creep rate. We suspected inhomogeneous heating because prior thermal mapping of the joint done with an infrared (IR) camera seemed to reveal gradients and thermal spikes near the interface, which could plausibly be associated with the intermetallic layer. ${ }^{1,2}$

Further analysis of the IR data showed, however, that the apparent thermal gradients were, in fact, emissivity gradients due to changes in phase and in the optical characteristics of the surface with no necessary connection to the thermal profile. An example of the raw data is shown in Fig. 5a, which shows an uncorrected plot of IR intensity versus distance (taken with $4000 \mathrm{~A} / \mathrm{cm}^{2}$ imposed on the sample). It shows a spike in (presumably) homogeneous
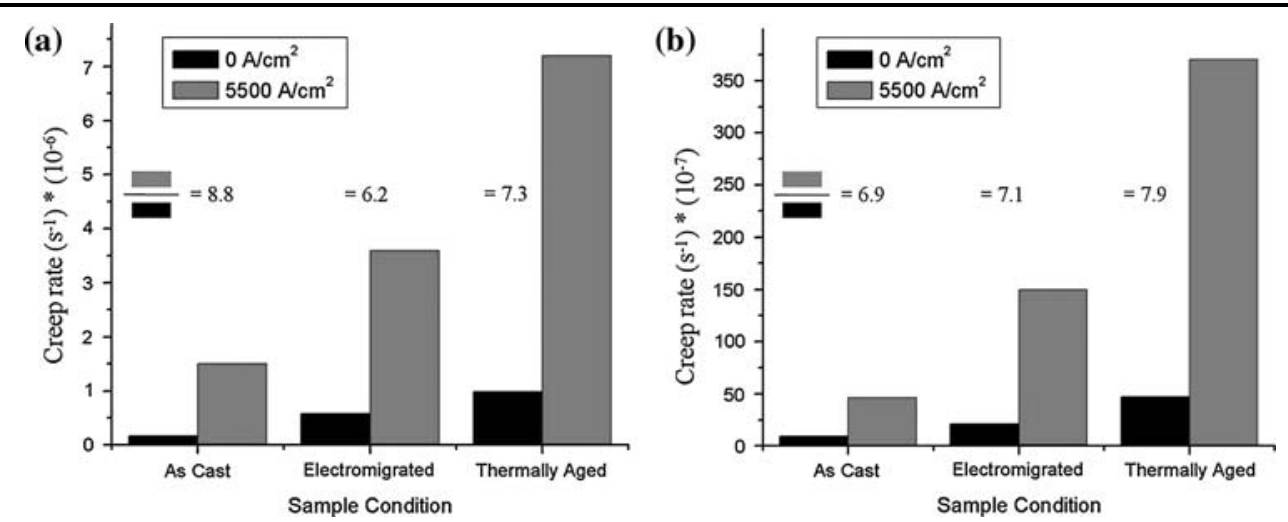

Fig. 3. Steady-state creep rates for three joint microstructures, with and without imposed current: (a) tested at $8.3 \mathrm{MPa}$ at $20^{\circ} \mathrm{C}$, and (b) at $3.5 \mathrm{MPa}$ at $80^{\circ} \mathrm{C}$. 

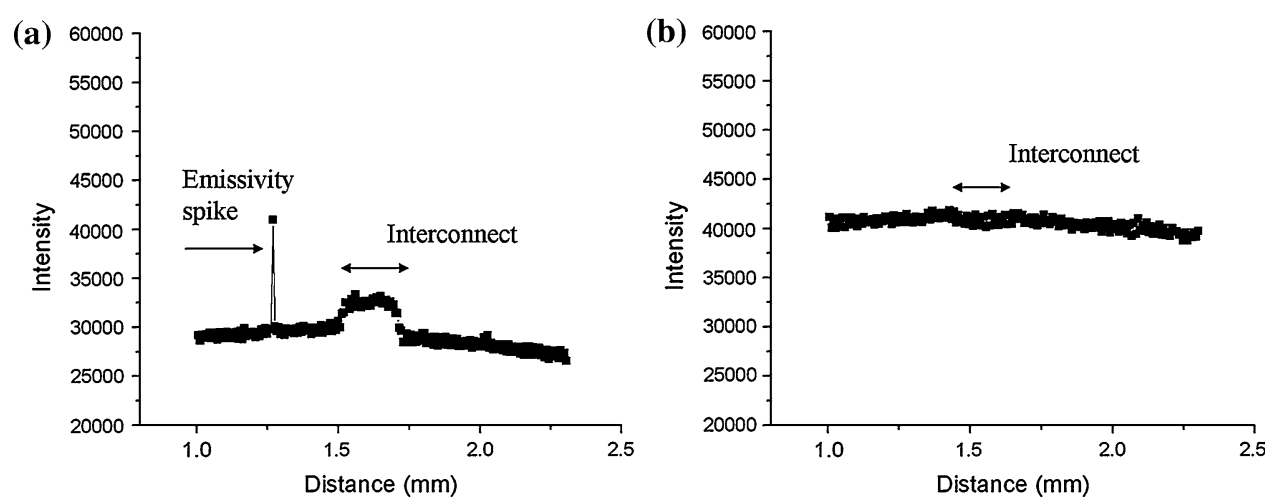

Fig. 5. Plot of IR data, intensity versus distance: (a) uncorrected data, and (b) data corrected for emissivity.

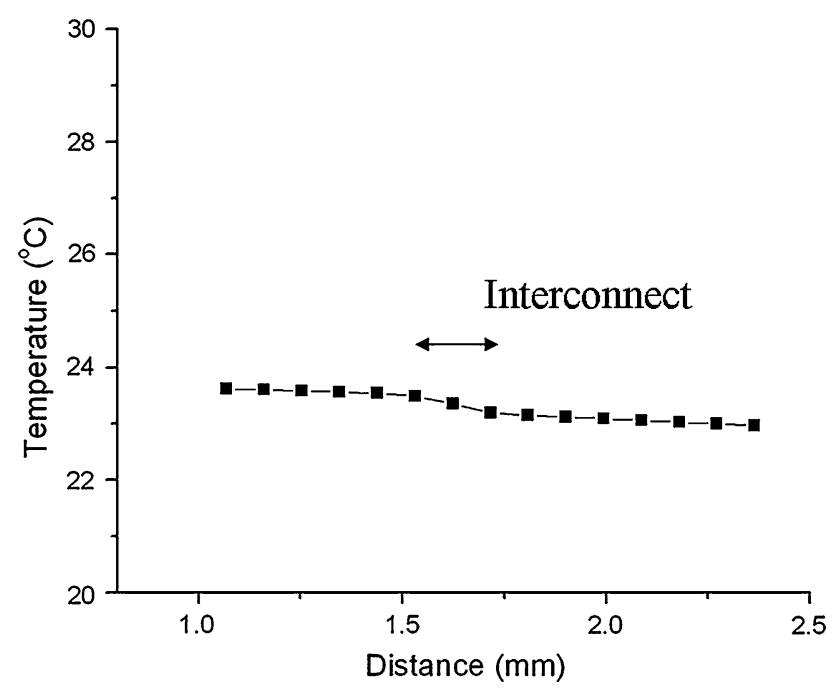

Fig. 6. The computed line profile of temperature across the sample. The two ends of the sample are set to $20^{\circ} \mathrm{C}$ via boundary conditions.

$\mathrm{Cu}$, and a step increase in the solder joint. To investigate which of these features are surface artifacts we repeated the experiment on a sample coated with a thin layer of black optical paint. The resulting profile is smooth, with a soft gradient to a relatively featureless maximum at the joint. The temperature within the joint is nearly constant.

This result was confirmed by calculations using two- and three-dimensional finite-element models of the samples. A temperature profile calculated using the finite-element software for $4000 \mathrm{~A} / \mathrm{cm}^{2}$ is shown in Fig. 6. Given the high thermal conductivity of the $\mathrm{Cu}$ metallization and the relatively small difference in resistivity between the intermetallic layer and the solder bulk, the temperature gradient is small and the temperature within the joint is almost constant; it varies by less than $0.2^{\circ} \mathrm{C}$.

It follows that the solder joints have an almost uniform, constant temperature during these tests, even when subjected to a current density of 5500 $\mathrm{A} / \mathrm{cm}^{2}$. The temperature measured by the thermocouples embedded in the joint should be accurate and applicable to the joint as a whole.

\section{Vacancy Flux Under Electromigration}

The second factor that may affect the creep behavior is the current-driven vacancy flux. In Snrich solders the electron current pushes Sn toward the anode, causing a counterflow of vacancies toward the cathode. If the vacancy flux is greater than can be accommodated by the available vacancy sinks and sources, the current will produce a gradient in vacancy concentration that will induce heterogeneity in the creep rate and, ordinarily, a change in the average creep rate over the joint cross-section.

While we cannot measure the vacancy concentration directly, there is clear indirect evidence of the current-induced vacancy flux. Figure 7 compares the pattern of creep in joints tested at the same temperature with and without current. Figure 7a shows the isothermal sample. The scribe marks on the sample surface are uniformly tilted, except for a small boundary effect at the two sides. This expected morphology reflects the constant creep rate that is expected under isothermal conditions. Figure $7 \mathrm{~b}$ shows the sample after creep at the same load and temperature, but under a current of $4000 \mathrm{~A} / \mathrm{cm}^{2}$. The scribe marks are curved into something like an S-shape, showing a heterogeneity in the creep rate. Since the temperature is essentially constant, the simple explanation for this behavior is a heterogeneous vacancy concentration due to the current-driven flux.

The current-driven vacancy flux is also the likely source of the voids located along the left-hand (cathode) side of the joint in Fig. 7b. Note that these voids are vacancy sinks that will maintain the vacancy concentration near the thermal equilibrium value at the cathode end. The common vacancy sources in electromigration are hillocks. No pronounced hillock formation is observed at the anode (right-hand) interface. If we sweep vacancies from an anode that has few sources to a cathode that is populated with sinks, the net effect should be a gradient in the vacancy concentration from a relatively low value to a value close to thermal equilibrium. As discussed below, this observation is consistent with the creep behavior we have observed. 

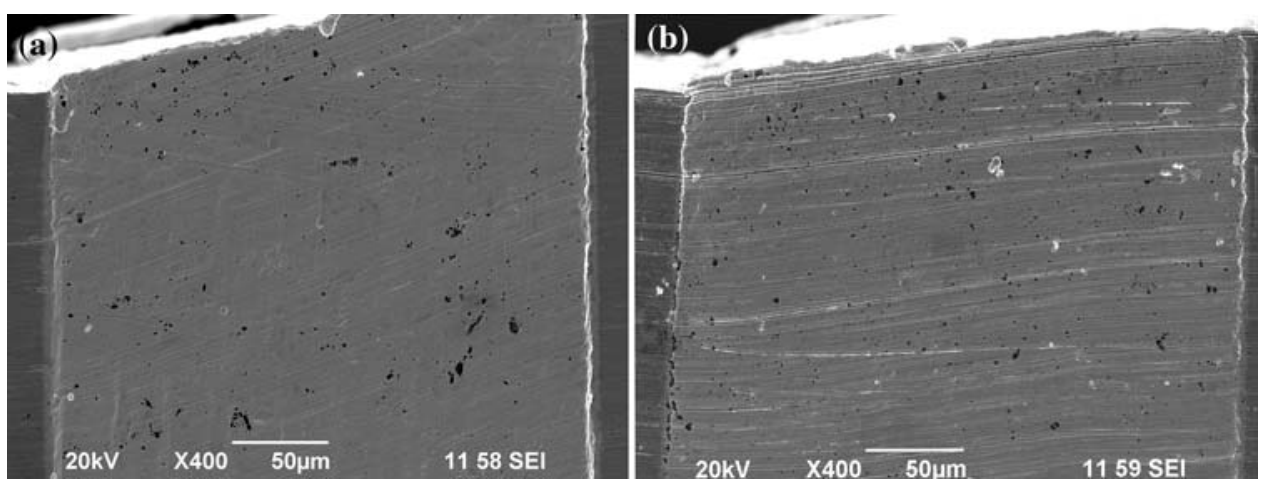

Fig. 7. Post-deformation image of scribe marks on samples: (a) after isothermal creep at $40^{\circ} \mathrm{C}$, and (b) after creep under $4000 \mathrm{~A} / \mathrm{cm}^{2}$.

In the next section we use the familiar Dorn equation to assess the influence of the currentdriven vacancy flux on the average creep rate, and show that, given constant temperature across the joint, it provides a straightforward explanation for the observed influence of current on creep.

\section{DISCUSSION}

Given that the temperature in the joint is nearly constant in our experiments, the phenomena we observed appear to have rather simple explanations.

\section{The Influence of Current on Creep Rate at Equivalent Temperature}

First consider the influence of current on the creep rate at a given temperature. The creep rate at the temperatures and stresses of interest here is well described by the familiar Dorn equation, ${ }^{13,14}$ which for this case can be written

$$
\dot{\gamma}=\frac{\mathrm{d} \gamma}{\mathrm{d} t}=A\left[\frac{D G b}{k T}\right]\left(\frac{\tau}{G}\right)^{n}
$$

where $\mathrm{d} \gamma / \mathrm{d} t$ is the steady-state strain rate, $\tau$ is the shear stress, $G$ is the shear modulus, $b$ is the Burgers vector, $D$ is the diffusivity, $T$ is the absolute temperature, and $A$ and $n$ are constants.

The diffusivity, $D$, should be the value that governs climb in a Sn-rich alloy, which we take to be the self-diffusion coefficient of $\mathrm{Sn}$. The self-diffusion coefficient can be written

$$
D=D_{0} x_{\mathrm{v}} \exp \left[-\frac{Q_{\mathrm{m}}}{k T}\right]=D_{0} \exp \left[-\frac{Q_{\mathrm{D}}}{k T}\right],
$$

where $x_{\mathrm{v}}$ is the concentration of lattice vacancies and $Q_{m}$ is the activation energy for atom migration into a vacancy. At thermal equilibrium

$$
x_{\mathrm{v}}=x_{\mathrm{v}}^{\mathrm{e}}=\exp \left[-\frac{Q_{\mathrm{v}}}{k T}\right],
$$

where $Q_{\mathrm{v}}$ is the activation energy for vacancy formation (and we have neglected a small entropy term). The second form of Eq. 2 assumes equilibrium vacancy concentration, in which case
$Q_{\mathrm{D}}=Q_{\mathrm{m}}+Q_{\mathrm{v}}$. If the vacancy concentration, $x_{\mathrm{v}}$, differs from the equilibrium value the diffusivity can be written

$$
D\left(x_{\mathrm{v}}, T\right)=D_{0}\left[\frac{x_{\mathrm{v}}}{x_{\mathrm{v}}^{\mathrm{e}}}\right] \exp \left[-\frac{Q_{\mathrm{D}}}{k T}\right]=\left[\frac{x_{\mathrm{v}}}{x_{\mathrm{v}}^{\mathrm{e}}}\right] D^{\mathrm{e}}(T),
$$

where $D^{\mathrm{e}}(T)$ is the equilibrium value of the diffusivity. Since the creep rate is linear in $D$, it is also linear in the local vacancy concentration, $x_{\mathrm{v}}$. It follows that a nonequilibrium vacancy concentration changes the creep rate to

$$
\dot{\gamma}=A\left[\frac{x_{\mathrm{v}}}{x_{\mathrm{v}}^{\mathrm{e}}}\right]\left[\frac{D^{\mathrm{e}} G b}{k T}\right]\left(\frac{\tau}{G}\right)^{n}=\left[\frac{x_{\mathrm{v}}}{x_{\mathrm{v}}^{\mathrm{e}}}\right] \dot{\gamma}^{\mathrm{e}},
$$

where $\dot{\gamma}^{\mathrm{e}}$ is the value of the creep rate at vacancy equilibrium.

In the tests we have reported here the creep rate, $\dot{\gamma}$, is the macroscopic creep rate of the joint, which is the average of the local creep rate across the width of the joint. Since the local creep rate is linear in the local vacancy concentration, the strain rate of the joint is

$$
\dot{\gamma}=\left\langle\dot{\gamma}_{\text {loc }}\right\rangle=A\left[\frac{\left\langle x_{\mathrm{v}}\right\rangle}{x_{\mathrm{v}}^{\mathrm{e}}}\right]\left[\frac{D^{\mathrm{e}} G b}{k T}\right]\left(\frac{\tau}{G}\right)^{n}=\left[\frac{\left\langle x_{\mathrm{v}}\right\rangle}{x_{\mathrm{v}}^{\mathrm{e}}}\right] \dot{\gamma}^{\mathrm{e}},
$$

where $\dot{\gamma}_{\text {loc }}$ is the local value of the strain rate.

In the tests that compared creep rates with and without current at constant strain rate the samples that were under current showed few obvious hillocks at the anode, but evident voids at the cathode. They appear to have few efficient vacancy sources (hillocks) but ample vacancy sinks (voids) and should therefore have an average vacancy concentration below the equilibrium value. It follows that the creep rate under current should be lower than that in the absence of current at the same temperature. The data in Fig. 5 are consistent with this and suggest that

$$
f_{\mathrm{v}}(T, j)=\frac{\left\langle x_{\mathrm{v}}\right\rangle}{x_{\mathrm{v}}^{\mathrm{e}}}=\frac{\dot{\gamma}}{\dot{\gamma}^{\mathrm{e}}} \approx 0.3-0.4
$$

with the lower value measured for $4000 \mathrm{~A} / \mathrm{cm}^{2}$ and the higher for $5500 \mathrm{~A} / \mathrm{cm}^{2}$. (While $f_{\mathrm{v}}$ must be assumed to depend on $T$ and $j$, the limited data do 
not permit us to draw conclusions about that functional dependence.)

\section{The Effect of an Imposed Current on the Creep Rate}

Now consider the increase in the overall creep rate that occurs when a current is imposed. The increase includes at least two effects: the increase in creep rate due to Joule heating and the change in creep rate (a decrease in our case) due to vacancy depletion.

Let a current density, $j$, be imposed on a joint with initial temperature, $T_{0}$. Let Joule heating raise the temperature to $T$, and let the average vacancy concentration change to $\left\langle x_{\mathrm{v}}\right\rangle$, which will reflect both an increase due to heating and a decrease due to the sweeping action of the current. Using Eqs. 1, 2, and 6, the creep rate at a given stress increases by the ratio

$$
\begin{aligned}
\dot{\gamma}^{*}\left(T_{0}, j\right) & =\frac{\dot{\gamma}(j, T)}{\dot{\gamma}\left(T_{0}\right)}=\left[\frac{\left\langle x_{\mathrm{v}}\right\rangle}{x_{\mathrm{v}}^{e}}\right]\left(\frac{T_{0}}{T}\right)\left[\frac{D(T)}{D\left(T_{0}\right)}\right] \\
& =\left[\frac{\left\langle x_{\mathrm{v}}\right\rangle}{x_{\mathrm{v}}^{\mathrm{e}}}\right]\left(\frac{T_{0}}{T}\right) \exp \left[\frac{Q_{\mathrm{D}}}{k}\left(\frac{1}{T_{0}}-\frac{1}{T}\right)\right] \\
& =f_{\mathrm{v}}(T, j)\left(\frac{T_{0}}{T}\right) \exp \left[\frac{Q_{\mathrm{D}}}{k}\left(\frac{\Delta T}{T T_{0}}\right)\right],
\end{aligned}
$$

where $\Delta T=\left(T-T_{0}\right)$.

We can test whether this analysis is reasonable by substituting the experimental values reported above for $\dot{\gamma}^{*}, f_{\mathrm{v}}$ and $\Delta T$ to see if they predict a plausible value of the activation energy, $Q_{\mathrm{D}}$, where

$$
\frac{Q_{\mathrm{D}}}{k}=\frac{T T_{0}}{\Delta T} \ln \left[\frac{\dot{\gamma}^{*}}{f_{\mathrm{v}}}\left(\frac{T}{T_{0}}\right)\right] .
$$

When a current density of $5500 \mathrm{~A} / \mathrm{cm}^{2}$ is imposed on a joint that is initially at ambient temperature, we have $\dot{\gamma}^{*} \sim 7, f_{\mathrm{v}} \sim 0.38, T_{0}=293 \mathrm{~K}$, and $\Delta T \sim 30 \mathrm{~K}$. With these values $Q_{\mathrm{D}} / k \approx 9500 \mathrm{~K}$, giving an activation energy,

$$
Q_{\mathrm{D}} \sim 0.82(\mathrm{eV} / \text { atom }) \sim 80(\mathrm{~kJ} / \mathrm{mole}) .
$$

This value of the activation energy is slightly below the most widely cited activation energy for the creep of SAC 305, which is a bit over $100 \mathrm{~kJ} / \mathrm{mole}^{4,7,8}$ but is well inside the range of measured values, $\sim 60 \mathrm{~kJ} / \mathrm{mole}$ to $\sim 110 \mathrm{~kJ} / \mathrm{mole}$. Given the natural scatter in creep rates, and the very limited data available here, the computed activation energy seems reasonable, and suggests that at least most of the physics of the phenomenon are captured in Eqs. 6 and 8.

\section{Insensitivity to Microstructure and Creep Rate}

The experimental data reported in the first part of this paper suggests that the relative creep rate, $\dot{\gamma}^{*}$, is surprisingly constant, being almost insensitive to both the microstructure and the initial temperature.
The fact that $\dot{\gamma}^{*}$ does not depend strongly on the microstructure has a simple, plausible explanation. The bulk of prior research on the creep of solders suggests that the microstructure enters the Dorn equation, Eq. 1, through its effect on the pre-exponential factor, $A$. In fact, the Dorn equation is often written to break out specific microstructural features, such as the grain size, that we have included in $A$. Since imposition of a current does not change the microstructure (at least not immediately), there will be some period of time during which $\dot{\gamma}^{*}$ is not affected. We expect that it will change after longterm exposure, when the heating and electromigration caused by the current have produced enough of a change in the microstructure to alter the value of the pre-exponential factor.

The fact that $\dot{\gamma}^{*}$ did not depend on the starting temperature, $T_{0}$, in these tests is more difficult to explain. Finite-element calculations suggest that the temperature increment, $\Delta T$ in Eq. 8, is nearly the same for $T_{0}=80^{\circ} \mathrm{C}$ and for $20^{\circ} \mathrm{C}$. If we were to also assume that the factors $f_{\mathrm{v}}$ is insensitive or constant when $T_{0}$ is changed, then the value of $\dot{\gamma}^{*}$ for $5500 \mathrm{~A} / \mathrm{cm}^{2}$ at $80^{\circ} \mathrm{C}$ should be about half its value for the same current density at $20^{\circ} \mathrm{C}$. In our tests it hardly changed at all.

\section{Decrease in Creep Rate with Current}

As shown in Eq. 6 the steady-state creep rate at a given temperature changes with current because the current alters the mean vacancy concentration, $\left\langle x_{\mathrm{v}}\right\rangle$. In our case $\left\langle x_{\mathrm{v}}\right\rangle$ appears to decrease significantly. This result is easily interpreted, even without a detailed model, since the joint contains vacancy sinks in the form of voids at the cathode, but no obvious efficient vacancy sources. If vacancies are swept from the anode faster than they can be replenished, and are efficiently consumed at the cathode, then we expect a vacancy concentration gradient that peaks at a value near thermal equilibrium at the cathode and has an average significantly below the thermal equilibrium value. This is consistent with our experimental data.

It should be noted, however, that different vacancy concentration profiles will lead to different results. For example, if the sample were so constituted that it had efficient vacancy sources at the anode but no vacancy sinks, then the average vacancy content would be above thermal equilibrium and the current would increase the creep rate.

We would also ordinarily expect an increase in the creep rate under conditions that impose thermal gradients on the joint. Given the exponential increase in vacancy concentration with temperature, and the rapid diffusion of vacancies, a local region of high temperature can act as a vacancy pump, increasing the vacancy concentration and creep rate in the cooler region around it. In fact, the acceleration of diffusional processes in a temperature gradient is a well-known phenomenon. 


\section{CONCLUSION}

The influence of current on the creep rate in a solder joint is a balance between the increase in creep rate due to Joule heating and the change (decrease in our case) due to the current-induced modification of the average vacancy content. The effect appears to be well described by the Dorn equation, which can be used for a quantitative as well as a qualitative treatment of the phenomenon, at least in the simple geometry tested here, where the imposition of current does not produce significant temperature gradients.

\section{ACKNOWLEDGEMENT}

This research was supported by the Component Quality and Technology Group, Cisco Systems.

\section{OPEN ACCESS}

This article is distributed under the terms of the Creative Commons Attribution Noncommercial License which permits any noncommercial use, distribution, and reproduction in any medium, provided the original author(s) and source are credited.

\section{REFERENCES}

1. C. Kinney, J.W. Morris, T.K. Lee, K.C. Liu, X. Jie, and D. Towne, JEM 38, 221 (2009). doi:10.1007/s11664-008-0568-3.

2. T.K. Lee, F. Hua, and J.W. Morris, Electron. Mater. Lett. 2, 157 (2006).

3. K. Yamanaka, Y. Tsukada, and K. Suganuma, Microelectron. Reliab. 47, 1280 (2007). doi:10.1016/j.microrel.2006.09. 028.

4. H.G. Song, J.W. Morris, and F. Hua, JOM 54, 30 (2002). doi:10.1007/BF02701846.

5. S. Park, R. Dhakal, L. Lehman, and E. Cotts, Acta Mater. 55, 3253 (2007). doi:10.1016/j.actamat.2007.01.028.

6. J. Sundelin, S. Nurmi, T. Lepisto, and E. Ristolainen, Mater. Sci. Eng. 420, 55 (2006). doi:10.1016/j.msea.2006.01.065.

7. S. Wiese and K.-J. Wolter, Microelectron. Reliab. 44, 1923 (2004). doi:10.1016/j.microrel.2004.04.016.

8. S. Wiese and K.-J. Wolter, Microelectron. Reliab. 47, 223 (2007). doi:10.1016/j.microrel.2006.09.006.

9. W. Peng, E. Monlevade, and M. Marques, Microelectron. Reliab. 47, 2161 (2007).

10. H.B. Huntington and A.R. Grone, J. Phys. Chem. Solids 20, 76 (1961). doi:10.1016/0022-3697(61)90138-X.

11. I.A. Blech, Thin Solid Films 13, 117 (1972). doi:10.1016/ 0040-6090(72)90164-2.

12. I.A. Blech, Acta Mater. 46, 3717 (1998). doi:10.1016/S13596454(97)00446-1.

13. J.E. Dorn, J. Mech. Phys. Solids 3, 85 (1954).

14. J. Harper and J.E. Dorn, Acta Metall. 5, 654 (1957). doi:10.1016/0001-6160(57)90112-8. 